\title{
Role of kitchen gardening in diet diversification and nutritional security
}

\author{
Veena Shahi, Pushpa Singh, Vikas Kumar and Rohit Maurya
}

See end of the paper for authors' affiliations Veena Shahi

Krishi Vigyan Kendra, Turki, Muzaffarpur (Bihar) India Email : veenashahi07@gmail. com

Received: 09.05.2019; Revised: 06.10.2019; Accepted: 20.10.2019

ABSTRACT : Kitchen gardening is the revolutionary step to increase vegetables production as well as provision of cheap vegetables to the consumers. The main focus of the study was to assess the role of kitchen gardening on nutrition security of rural household. A total of 60 rural women were selected to assess the impact of kitchen gardening by random sampling method that has undergone the training programme at KVK Vaishali and Muzaffarpur (Additional). Results showed that an increase in the knowledge of participants after their participation in training on various aspects of kitchen gardening. Unavailability of quality seed material was the major constraint $(83.33 \%)$ for production of vegetables in kitchen garden. Low availability of water for irrigation and adoption of traditional practices for growing vegetables ranked second and third constraint, respectively. After getting training on kitchen garden from KVK, farm families get fresh and organic vegetables year round and their nutritional needs are fulfilled. The average yield of the vegetables increased from $30.5 \mathrm{~kg} / \mathrm{unit}$ in farmers practice to $110 \mathrm{~kg} / \mathrm{unit}$ under recommended practice. Results also revealed 60 per cent increase in the average per capita consumption of vegetables. After demonstration, consumption of vegetables increased, especially of green and leafy vegetables. Homestead kitchen gardening along with nutrition intervention will improve the nutritional security and health in rural livelihoods, but the approach is normally slow and results are achieved over a long run.

KEY WORDS: Diet diversification, Malnutrition, Nutritional garden, Nutritional security

- HOW TO CITE THIS PAPER : Shahi, Veena, Singh, Pushpa, Kumar, Vikas and Maurya, Rohit (2019). Role of kitchen gardening in diet diversification and nutritional security. Asian J. Home Sci., 14 (2) : 288292, DOI: 10.15740/HAS/AJHS/14.2/288-292. Copyright@ 2019: Hind Agri-Horticultural Society. 